\title{
Movilidad cotidiana de la población trabajadora en la Zona Metropolitana de Monterrey, 2015
}

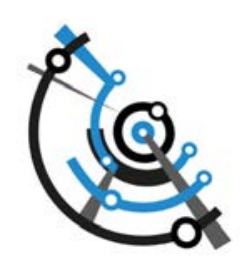

\section{( José Alfredo Jáuregui Díaz}

Instituto de Investigaciones Sociales, Universidad Autónoma de Nuevo León, México. https://orcid.org/oooo-0002-2518-8818

\section{María de Jesús Ávila Sánchez}

Instituto de Investigaciones Sociales, Universidad Autónoma de Nuevo León, México. https://orcid.org/oooo-0002-8693-4634

\section{Rodrigo Tovar Cabañas}

Instituto de Investigaciones Sociales, Universidad Autónoma de Nuevo León, México. https://orcid.org/oooo-0003-4873-2502

Recibido: 17 de octubre de 2019. Aceptado: 30 de junio de 2020.

\begin{abstract}
Resumen
El objetivo del presente trabajo es examinar la movilidad cotidiana relacionada con el trabajo en la Zona Metropolitana de Monterrey (ZMM) un espacio geográfico conformado por 18 municipios, utilizando como fuente primaria de información los microdatos de la Encuesta Intercensal realizada en el año 2015 por el Instituto Nacional de Geografía y Estadística (INEGI) y las preguntas del módulo de movilidad cotidiana: tiempo de viaje y principal medio de transporte. Además, se realizan diferenciaciones entre la población trabajadora según la ubicación del municipio de residencia y el municipio de trabajo. Los resultados muestran una caótica movilidad cotidiana en la ZMM, vivir en el mismo municipio donde se trabaja marca una gran diferencia al invertir menos tiempo en el traslado diario. El automóvil juega un papel destacado en la movilidad y es un elemento de desigualdad social.
\end{abstract}

Palabras claves: Movilidad cotidiana. Desigualdad social. Zona Metropolitana de Monterrey. Trabajo. Transporte. 


\title{
Daily mobility of the working population in the Monterrey Metropolitan Area, 2015
}

\begin{abstract}
The objective of the present work is to examine the daily mobility related to work in the Monterrey Metropolitan Area (ZMM), a geographic space made up of 18 municipalities, using as micro-data the Intercensal Survey carried out in 2015 by the National Institute of Geography and Statistics (INEGI) and questions from the daily mobility module: travel time and main means of transport. In addition, differentiations are made between the working population according to the location of the municipality of residence and the municipality of work. The results show a chaotic daily mobility in the ZMM, living in the same municipality where you work makes a big difference by spending less time on the daily commute. The automobile plays a prominent role in mobility and is an element of social inequality.
\end{abstract}

Key words: Daily mobility. Social inequality. Monterrey Metropolitan Area. Job. Transport. Palavras-chave: Mobilidade diária. Desigualdade social. Área metropolitana de Monterrey. Trabalho. Transporte.

\section{Introducción}

El proceso de urbanización de México, desde los años sesenta del siglo pasado a la fecha, se ha caracterizado por seguir un modelo urbano de expansión y fragmentación de las áreas (Sabrino, 2007). Como resultado las Zonas Metropolitanas (ZM) en el país registraron un crecimiento exponencial en cantidad de población y extensión territorial, al ir agregando nuevos espacios geográficos contiguos al municipio central en la búsqueda de territorios urbanizable para asentamiento de nuevos polos industriales e inmobiliarios.

En 1960 solo había 12 ZM en México para el año 2015 eran 74, las implicaciones de este modelo urbano expansivo son diversas, desde los impactos sociales que se traducen en mayor desigualdad social producto de la segregación residencial, hasta ambientales debido al alto consumo de tierras y recursos. El lugar de residencia y de trabajo se encuentra cada vez a mayor distancia, implicando mayor inversión de tiempo de traslado y la utilización del automóvil privado como principal medio de transporte (Delclòs, 2019).

El estado de Nuevo León, no ha sido la excepción, dentro de su territorio se ubica la tercera ZM más importante en México, referida como Zona Metropolitana de Monterrey (ZMM), nominada como el municipio central. El proceso de metropolización ha sido rápido, en 1950 estaba conformada la mancha urbana por tres municipios Monterrey, Guadalupe y San Nicolás de los Garza, un espacio geográfico de 502,7 km2 con una población de 362,4 mil habitantes (Garza, 1994).

El proceso de metropolización no ha cesado, en el año 2015 la ZMM abarca una extensión territorial de 7.627,5 km2 que abarca 18 municipios: Abasolo, Apodaca, Cadereyta Jiménez, El Carmen, Ciénega de Flores, García, San Pedro Garza García, General Escobedo, General Zuazua, Guadalupe, Juárez, Monterrey, Pesquería, Salinas Victoria, San Nicolás de los Garza, Hidalgo, Santa Catarina y Santiago, donde residen 4,7 millones de personas equivalentes al 90,6\% de la población total del estado de Nuevo León (CONAPO, SEDESOL e INEGI, 2018).

Diversos factores han contribuido al crecimiento de la mancha urbana de la ZMM, entre los que sobresalen: 
» La concentración en su territorio de la mayoría de las actividades económicas industriales, comerciales y de servicios que se desarrolla en la entidad (Jurado y Pereira, 2010; Soto, 2017).

» El desarrollo industrial, que genera una oferta de empleo superior a la demanda local (Soto, 2017).

» El asentamiento en espacios geográficos periféricos de industrias nuevas, el caso más reciente es la armadora automotriz coreana KIA Motors en el municipio de Pesquería.

" La construcción de vivienda nueva a grandes distancias con respecto a la ciudad central, se han aprobado fraccionamientos nuevos del segmento medio hasta una distancia de 23 kilómetros (Soto, 2015).

» Los procesos de inmigración de personas en edades laborales para cubrir la demanda de empleo, provenientes tanto del interior de Nuevo León como de entidades contiguas como Coahuila, Tamaulipas, San Luis Potosí y Zacatecas. Con el paso del tiempo los lugares de origen de las personas migrantes se han diversificado, hoy en día llegan migrantes de todo el país (Bedoya, Jáuregui, Ávila y Picazzo, 2018), que se asientan por lo general en municipios alejados del lugar central (Soto, 2017).

Entre 1951 y 2015 fueron absorbidos por la ZMM quince municipios adicionales, Abasolo, Apodaca, Cadereyta Jiménez, El Carmen, Ciénega de Flores, García, General Escobedo, San Pedro Garza García, General Zuazua, Juárez, Pesquería, Salinas Victoria, Hidalgo, Santa Catarina y Santiago, a las tres iniciales Monterrey, Guadalupe y San Nicolás de los Garza.

El acelerado crecimiento poblacional dentro de la ZMM ha tenido variaciones temporales y espaciales, por ejemplo, Apodaca fue la demarcación que creció con mayor velocidad durante el decenio 1990-2000 registrando una tasa media de 9,4\% anual, en otras palabras, en el periodo referido su población se multiplicó 2,3 veces, otros municipios con niveles de crecimiento altos fueron: García, General Escobedo, Salinas Victoria y Ciénega de Flores. Durante el siguiente lustro 2010-2015, el municipio con mayor crecimiento poblacional en la entidad fue Pesquería con una tasa media anual del $35,1 \%$, periodo en que la población se multiplicó 4,2 veces al pasar de 20.843 a 87.168 personas.

La configuración territorial expansiva, dispersa y la especulación inmobiliaria en la ZMM hace difícil residir cerca de donde se labora, los trabajadores invierten una buena parte de su tiempo de vida en recorrer diariamente largas distancias, entre su casa y los centros de trabajo, que varían según características individuales y variables sociodemográficas.

En el presente documento se plantea como objetivo conocer las características de la movilidad de las personas relacionada con el trabajo en la ZMM, para ello se emplea el paradigma de la movilidad cotidiana, el modo de transporte y costo para desplazarse al trabajo (Delclòs, 2019). Se parte del supuesto que el trabajo involucra patrones y experiencia de la movilidad entrelazados con la configuración territorial y las características individuales.

Para su realización se utilizó como fuente primaria de información los microdatos de la Encuesta Intercensal del año 2015 que permite calcular datos sobre la movilidad cotidiana entre el lugar de residencia habitual y el centro de trabajo a partir de dos variables captadas: medio de transporte utilizado y tiempo de viaje, además es posible relacionar los resultados con otras variables contextuales de las personas.

El documento se encuentra estructurado en cuatro secciones, en la primera se expone un pequeño marco teórico; la segunda aborda la metodología; en la tercera se presentan los resultados; y en la cuarta se muestran las conclusiones. 


\section{De la movilidad espacial a la movilidad cotidiana}

Movilidad espacial es un concepto amplio que incluye diferentes tipos de desplazamiento, "una transferencia de un lugar a otro" (Cattan, 2018: 70), sin implicar un cambio de residencia habitual como la migración. Desde esta perspectiva se ha profundizado en el estudio en tres grandes líneas de investigación: time geography, commuter town y daily mobility, las cuales se presentan a continuación.

\section{Time geography (geografía del tiempo)}

A finales de los años sesenta del siglo pasado Hägerstrand desde una visión integradora, fue el primero en analizar la dinámica demográfico-espacial de la población utilizando la geografía del tiempo, al desarrollar modelos sobre las prácticas cotidianas o individuales, a fin de comprender los patrones espaciales, tales como: la concentración temporal, la complejidad de las redes de conveniencia, lo efímero de ciertos eventos cotidianos, y la eficientización del espacio-tiempo urbano (Hägerstrand, 1953; 1970).

El desarrollo de los sistemas de información geográfica y de un software especializado denominado Geotime permitió una rápida difusión de esta línea de investigación y su adopción en las ciencias sociales, a manera de ejemplo puede referirse el trabajo pionero de Rose (1993) denominado, "Feminism and geography: The limits of geographical knowledge" donde analiza como los caminos cotidianos trazados por los seres humanos están relacionados con el género y con una visión masculina que impide poner en práctica un enfoque feminista.

\section{Commuter town}

Las problemáticas de las commuter town, ciudades de cercanías o ciudades dormitorio, como también se les conoce, fueron documentadas por Walker (1976), un joven urbanista egresado de Instituto de Estudios Urbanos de la Universidad de Texas en Arlington, quien evidenció la dificultad de estudiantes y trabajadores residentes en el pueblo de Flower Mound para llegar al condado de Denton, situado a más de $20 \mathrm{~km}$. La solución de este pionero fue crear un sistema de ciclovías para bicicletas.

Al paso de los años se ha determinado que las ciudades de cercanías se originan principalmente por ciertos motivos, por ejemplo:

» Al perderse la principal fuente de empleo en una ciudad sus habitantes buscan trabajo en el siguiente eslabón de la jerarquía urbana sin cambiar su lugar de residencia.

"Las ciudades pequeñas con escenarios ambientales agradables atraen con el tiempo un mayor número de residentes, pero al no haber suficientes empleos para cubrir la demanda, las personas sueles desplazarse todos los días a otras ciudades para trabajar. Este tipo de estudios han sido retomados en los Países Bajos por Noort (2010).

En México los estudios sobre los commuter town se han centrado en los trabajadores transfronterizos, categoría asignada a las personas residentes en alguna ciudad de la frontera norte de México, con trabajo habitual ubicado en una ciudad estadounidense contigua (Vega, 2016), por ejemplo, mexicanos que viven en Tijuana o Mexicali y trabajan en San Diego o Calexico. Entre los principales hallazgos de investigación se han resaltado las asimetrías económicas entre los lugares de residencia y los destinos laborales, como señala Anguiano, en el área conurbada entre San Diego-Tijuana se visibilizan las desigualdades económicas entre México y Estados Unidos, San Diego una de las ciudades más ricas de Estados Unidos con Tijuana un lugar con alta proporción de pobres en México (Anguiano, 2005). 


\section{Daily mobility (Movilidad diaria)}

La doctora Law (1999), desde el denominado giro cultural, fue la primera en proponer alternativas para enriquecer el tema de la geografía del transporte con la introducción del concepto de movilidad diaria, al documentar las restricciones estructurales de la movilidad diaria de las mujeres.

En el año 2004 Kaufmann y Jemelin relacionan la daily mobility o movilidad diaria con la calidad de vida de las personas, clasificando la duración del desplazamiento entre los espacios geográficos de residencia y laboral en cuatro tipos: migración, movilidad residencial, viajes y movilidad cotidiana.

Los dos primeros, involucran un cambio de residencia habitual y se diferencian por el espacio geográfico donde se realiza. En la "migración" se traspasan fronteras jurídicas administrativas, como municipios, entidades o países, además el traslado puede ser a corta o larga distancia, en cambio la "movilidad residencial" ocurre al interior de zonas urbanas o metropolitanas.

El tercer tipo los "viajes" y el cuarto tipo "movilidad cotidiana" son desplazamientos temporales, sin que haya un cambio de residencia habitual, y se diferencian por el tiempo de duración de la estancia. Los "viajes" llegan a tener una temporalidad desde unas horas y pueden alargarse por días o semanas.

\section{La movilidad cotidiana}

La "movilidad cotidiana" ocurre diario, con propósitos específicos como ir a la escuela o al trabajo, con una duración de minutos u horas. Casado en el año 2008, define la movilidad cotidiana como prácticas habituales y reiteradas de desplazamientos de corta duración o distancia vinculadas a distintos fines, donde estadísticamente predominan los desplazamientos al trabajo y al lugar de estudio, son un reflejo de vínculos funcionales entre diversos espacios a escalas disímiles.

Delclòs en 2019 va más allá señalando como la movilidad cotidiana atiende a cuatro dimensiones:

"El propósito para movernos. La movilidad es una actividad derivada, sin propósito en sí, responde a una utilidad asociada a los ámbitos como el trabajo, las compras o el ocio.

"El espacio geográfico. La movilidad diaria de las personas ocurre en un espacio geográfico tema prioritario de la geografía (Gould, 1985).

"El modo de transporte. El entorno construido condiciona las opciones individuales de movilidad en el espacio geográfico. ${ }^{1}$

» El costo. La movilidad cotidiana tiene múltiples costos para las personas siendo estos, económicos, ambientales y en tiempo (Camagni et al., 2002).

La movilidad cotidiana está relacionada con la estructura territorial, ya que la ubicación espacial de las actividades humanas determina las distancias necesarias para cubrir la movilidad. Canales y Hernández (2017) señalan para Chile que la movilidad cotidiana de los trabajadores es reflejo de las diferencias en los patrones de localización de sus residencias respecto a los patrones de localización de sus empleos. En tanto, Badoe y Miller (2000) encontraron que las zonas metropolitanas que se basan en un modelo de segregación funcional provocan un aumento de la movilidad a largas distancias y por 
lo tanto una mayor dependencia a los medios de transporte motorizados. En cambio, los modelos de uso mixto del espacio, donde las actividades humanas están próximas unas de otras promueven los viajes cortos y los medios activos de transporte (Marquet y Miralles-Guasch, 2015).

\section{La movilidad cotidiana estudios empíricos en México}

Los estudios de la movilidad cotidiana en México se han concentrado en la zona metropolitana de la Ciudad de México la aglomeración urbana más grande del país, en el análisis de los efectos negativos del transporte, la creciente motorización y la contaminación atmosférica (Casado, 2008). De acuerdo con Isunza (2010) el tema había sido poco explorado antes del año 2000 debido a la falta de fuentes de información para estimar los flujos poblacionales intermunicipales.

Después de la publicación de los resultados de la muestra censal del año 2000 fue posible analizar el origen y destino de los flujos residenciales y laborales, con base en esta información se realizaron una serie de estudios sobre movilidad desde diferentes perspectivas que abarcan, entre otras: su relación con el transporte urbano, la vialidad y la contaminación ambiental (Islas , 2000; Fuentes, 2009); impacto en la configuración de nuevas centralidades en la estructura urbana (Graizbord, 2004), en la delimitación de zonas metropolitanas (Sobrino, 2007), articulación con el lugar de trabajo y residencia (Acuña y Graizbord, 1999), diferenciación social y por género (Lindón, 2020) y la relación con el mercado inmobiliario (Isunza, 2010).

Sin embargo, sobre la ZMM hay estudios de movilidad desde los años noventa del siglo pasado, en 1995 Quintanilla y Larralde en 1997coinciden en identificar una estructura urbana de tipo monocéntrico, aunque para Larralde existe una extensión del centro original Monterrey hacia la región continua en donde se comienza a formar un subcentro de actividad importante en el municipio de San Nicolás de los Garza.

Otro elemento a considerar es la relación entre la movilidad cotidiana con la configuración urbana y el transporte. El carácter monocéntrico de la ZMM se corrobora al comprobar que el municipio central Monterrey circulan el $80 \%$ de las rutas de transporte urbano, proporción que disminuye al $24 \%$ en Apodaca y al 6\% en García uno de los municipios de reciente incorporación a la mancha urbana.

Jurado y Pereira (2010) señalan como en la ZMM las áreas industriales, comerciales y de servicios, son lugares con poca población, cuyos residentes perciben ingresos medios y altos de manera que la mano de obra proviene de lugares alejados potencializando la movilidad. La situación se agudiza entre la población residente en la zona periférica, caracterizada por percibir menores ingresos por trabajo e invertir hasta un $60 \%$ en transporte público ${ }^{2}$. Para Soto (2017) el modelo de la estructura urbana de la ZMM presenta una mixtura entre monocéntrico e incluso policéntrica, aunque las dimensiones de los diversos subcentros urbanos no poseen ni diversidad ni consolidación, lo que complica la movilidad cotidiana.

2 Las personas con mayores ingresos económicos residen en lugares cercanos a su trabajo, debido a su capacidad de poder pagar el alto precio del suelo urbano, y por consiguiente reducir los tiempos de viaje al trabajo. En sentido contrario, las personas con menos ingresos económicos, suelen vivir en lugares distantes del centro de trabajo, invirtiendo una parte considerable de ingreso para trasladare, hecho consistente con los modelos neoclásicos de la economía urbana (Fuentes, 2009). 
Sin duda, las contribuciones de los estudios realizados son importantes, pero hace falta mucho por hacer. Es necesario continuar analizando en la ZMM la movilidad relacionada con el trabajo remunerado y los niveles de accesibilidad de acuerdo con las capacidades y características individuales considerando los problemas del transporte público (Bautista, 2019).

\section{Metodología}

En la elaboración de la investigación fue necesario delimitar el espacio geográfico de estudio y definir que se entenderá por ZMM, con este propósito se empleó la propuesta del Consejo Nacional de Población (CONAPO), la Secretaria de Desarrollo Social (SEDESOL) y el Instituto Nacional de Estadística y Geografía (INEGI) realizada en el año 2018, en el documento "Delimitación de las zonas metropolitanas de México 2015", donde la ZMM queda conformada por 18 municipios (Figura 1): Abasolo, Apodaca, Cadereyta Jiménez, El Carmen, Ciénega de Flores, García, San Pedro Garza García, General Escobedo, General Zuazua, Guadalupe, Juárez, Monterrey, Pesquería, Salinas Victoria, San Nicolás de los Garza, Hidalgo, Santa Catarina y Santiago (CONAPO, SEDESOL e INEGI, 2018).

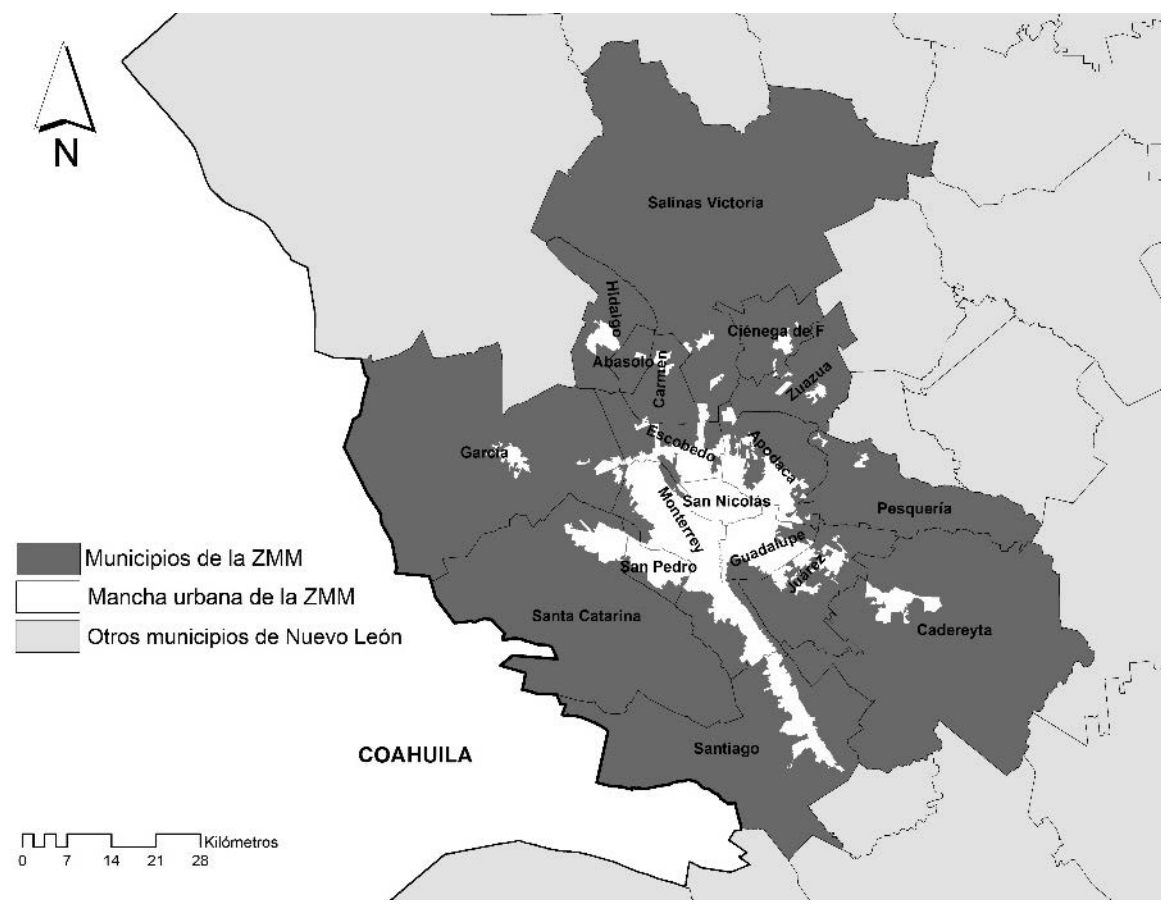

Figura 1. Zona Metropolitana de Monterrey, 2015. Fuente: Elaboración propia con base en los microdatos de la Encuesta Intercensal, 2015, INEGI.

Como el objetivo principal de este estudio es conocer la movilidad de la población trabajadora en la ZMM, se utiliza como guía el concepto movilidad cotidiana definido como el desplazamiento que realiza la población ocupada de 12 y más años, desde su lugar de residencia hasta su lugar de trabajo (INEGI, 2018). La fuente primaria de información empleada son los microdatos de la Encuesta Intercensal del año 2015 realizada por el Instituto de Nacional de Geografía y Estadística, a la fecha la encuesta con mayor robustez estadística realizada en México, con una muestra del $20 \%$ de la población permite realizar desagregaciones de información a diferentes niveles, nacional, estatal, municipal, para localidades urbanas de 50 mil habitantes o más y por otros tamaños de localidad. 
La Encuesta Intercensal incluyó una batería de preguntas sobre movilidad cotidiana de la población trabajadora, a partir de dos variables, tiempo de viaje y medios de transporte utilizados para ir al trabajo, con las cuales pueden calcularse datos al nivel de desagregación de interés que en este caso es la ZMM. A continuación, en la figura 2 se presentan las preguntas del cuestionario.

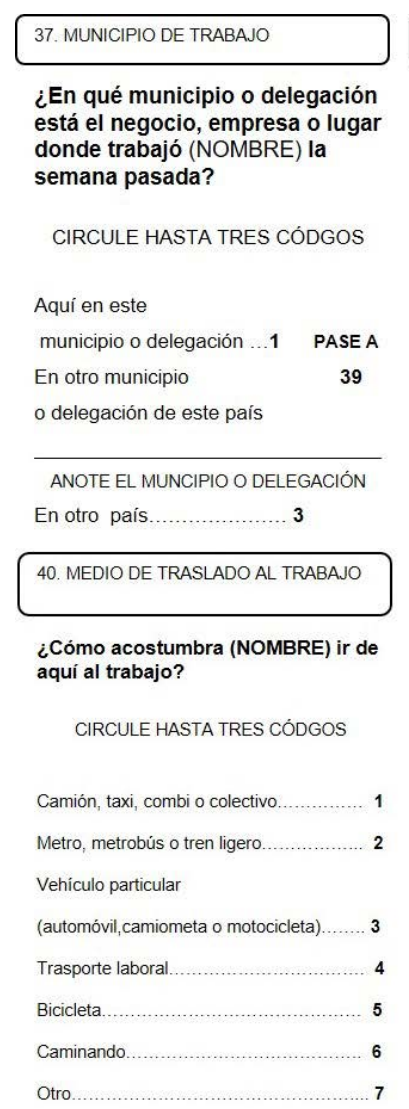

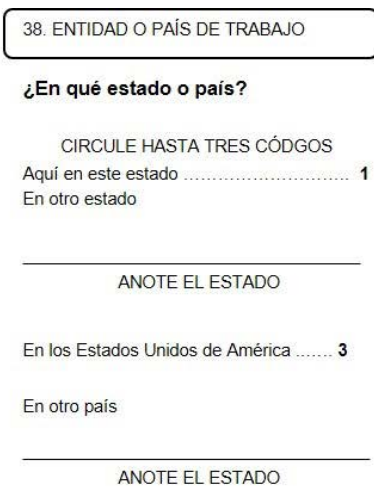

39. TIEMPO DE TRASLADO AL TRABAJO

¿Cuánto tiempo hace (NOMBRE) de aqui al trabajo?

CIRCULE HASTA TRES CÓDGOS

Hasta 15 minutos ................................ 1

16 a 30 minutos ............................... 2

31 minutos a 1 hora .............................. 3

Más de 1 hora y hasta $2 \ldots \ldots \ldots \ldots \ldots \ldots \ldots . . . . . . .4$

Más de 2 horas ………….................... 5

No es posible determinarlo...................... 6

No se traslada .................................. 7

Figura 2. Preguntas sobre movilidad cotidiana de la población trabajadora, 2015. Fuente: INEGI (2018:94).

Las preguntas solo se aplicaron a la población de 12 años y más que realizar una actividad económica, excluyendo a la población sin actividad económica, las niñas, niños $\mathrm{y}$ adolescentes, los cuales pudieran tener una movilidad cotidiana diferente.

\section{Resultados}

En el año 2015 había en Nuevo León 1,9 millones de personas insertas en el mercado laboral (12 años y más) ${ }^{3}$, en la ZMM se concentraba 89,2\% del total de esta población 1,7 millones, de las cuales 95 de cada 100 personas trabajan en algún municipio de la misma, el presente documento se enfoca en esta cohorte. En realidad, no debería ser problema trasladarse del lugar de residencia habitual al trabajo si la distancia fuera corta o existiera un sistema eficiente de transporte acorde a las necesidades de la población. 
Sin embargo, solo 56,5\% de la población trabajadora residen en el mismo municipio en donde vive, en contraparte, $42,5 \%$ vive y trabaja en un municipio distinto dentro del radio de la ZMM y el resto $1 \%$ tienen su empleo en otro municipio del estado u otra entidad (Figura 3). Residir y trabajar a una distancia corta en una ZM es difícil porque las personas se enfrentan a la manipulación del mercado inmobiliario (Soto, 2017:27), que obliga a los trabajadores a asentarse en lugares donde hay oferta de vivienda de bajo costo por lo general ubicada en municipios alejados de sus centros de trabajo.

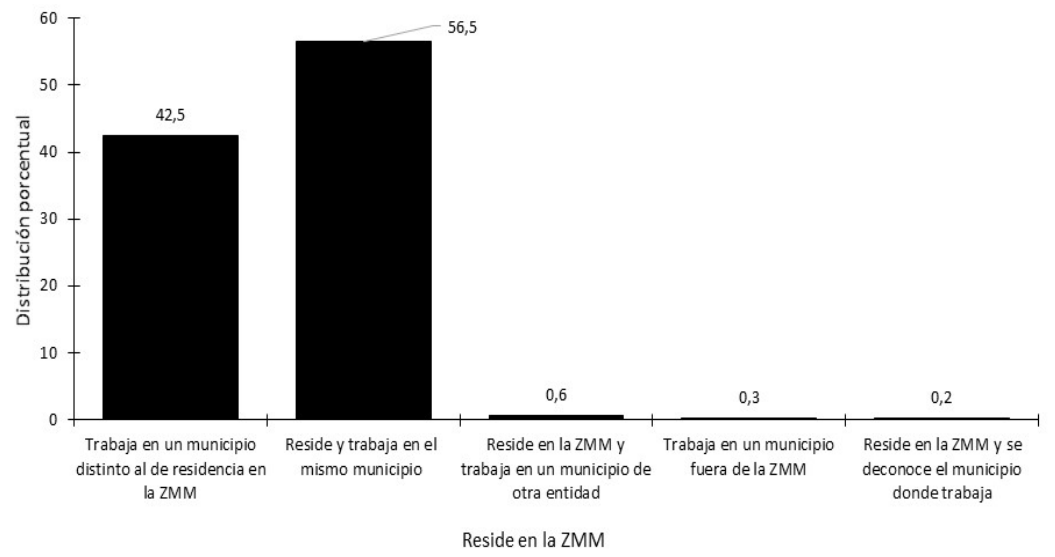

Figura 3. Población trabajadora que reside en la ZMM según ubicación geográfica del lugar de trabajo, 2015. Fuente: Elaboración propia con base en los microdatos de la Encuesta Intercensal, 2015, INEGI.

Analizando a la población trabajadora en los 18 municipios que integran la ZMM sobresale un panorama diverso, por un lado, en municipios como Cadereyta y Monterrey las proporciones de personas que viven y trabajan en el mismo municipio superan 80\%. Mientras que, por otro lado, en municipios como Pesquería, El Carmen, Juárez, General Zuazua, Abasolo y García más del 60\% de los trabajadores salen a laborar a otros municipios en la ZMM (Figura 4).

La alta proporción de personas residentes en un municipio diferente al lugar donde se encuentra su centro de trabajo, se explica por el proceso de expansión y dispersión de la mancha urbana, que traslada su crecimiento a municipios periféricos donde se concentra la oferta de vivienda de segmento medio y bajo, así como la disponibilidad de terrenos baratos ofertados por agentes inmobiliarios (Jurado y Pereira, 2010).

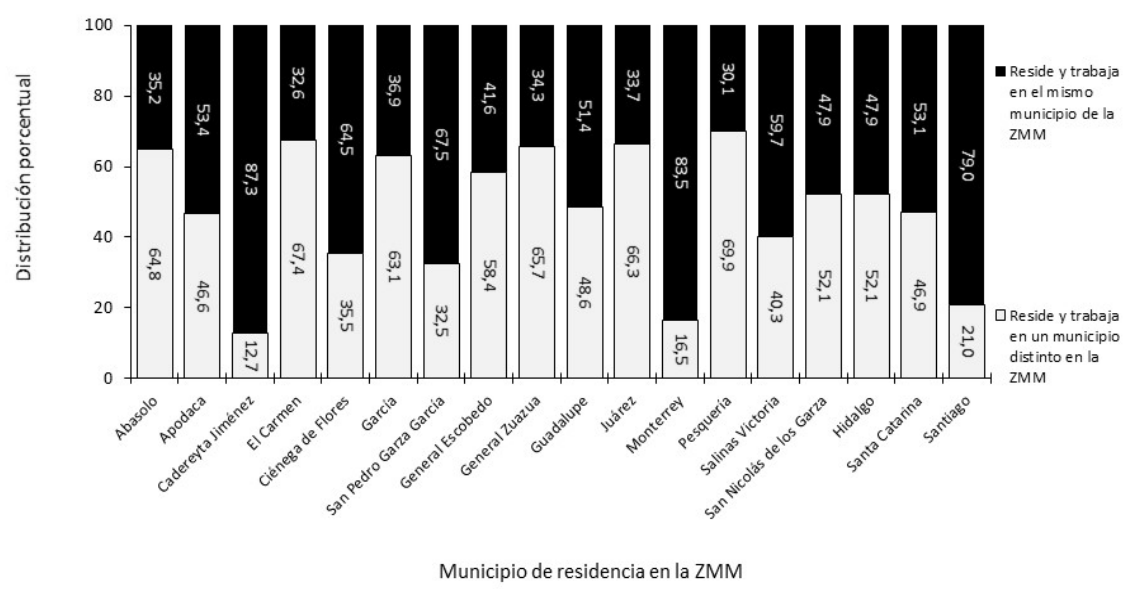

Figura 4. Población residente en la ZMM y ubicación del centro de trabajo por municipio, 2015. Fuente: Elaboración propia con base en los microdatos de la Encuesta Intercensal, 2015, INEGI. 
En la ZMM existen nodos donde se concentra la actividad laboral, así de las 816 mil personas que trabajan en un lugar diferente al de residencia, sobresale como nodo laboral principal o lugar central el municipio de Monterrey, y cuatro nodos laborales secundarios en los municipios de Apodaca, San Pedro Garza García, Guadalupe y San Nicolás de los Garza (Figura 5).

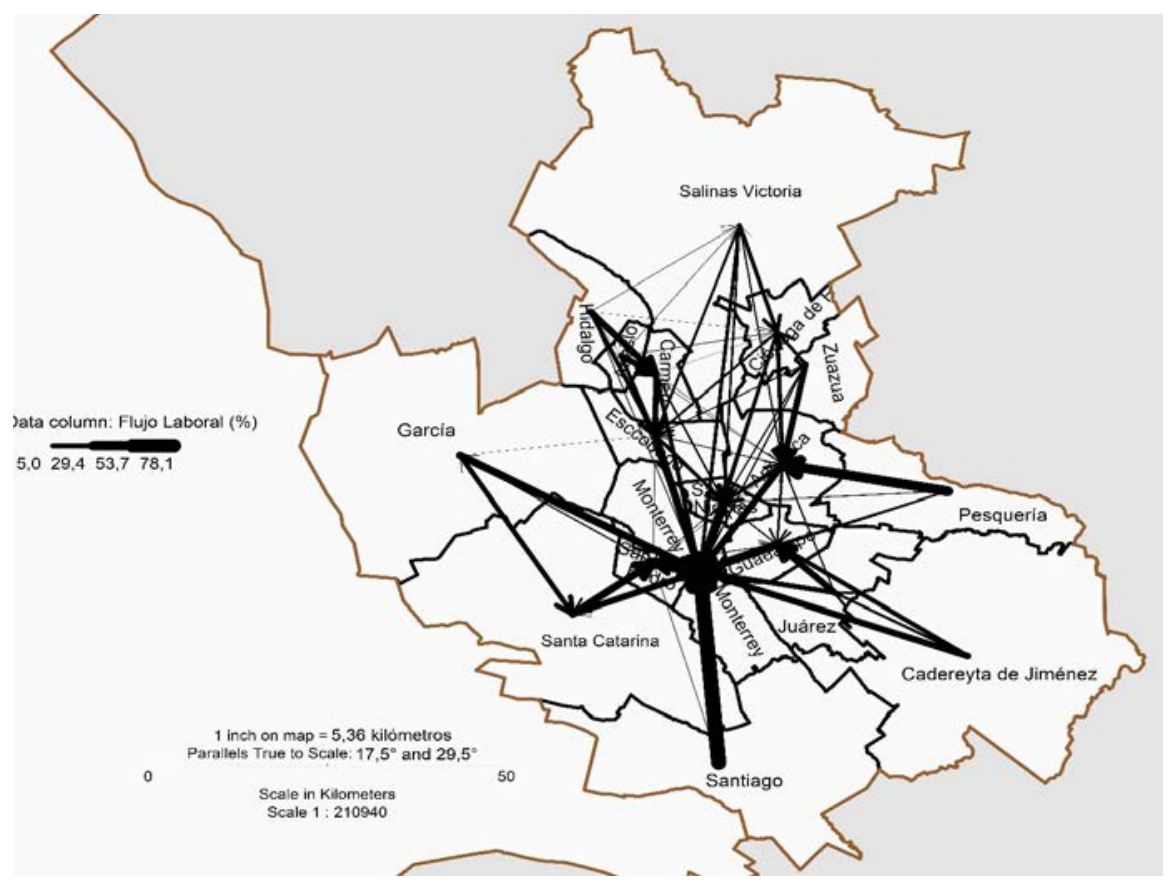

Figura 5. Movilidad cotidiana de la población trabajadora residente en la ZMM, 2015. Fuente: Elaboración propia con base en los microdatos de la Encuesta Intercensal, 2015, INEGI.

Los datos presentados corroboran los hallazgos de Quintanilla (1995) que sugería con datos del año 1990 la formación incipiente de cuatro subcentros dentro de la ZMM y no solo dos como proponía Larralde (1997). Además, se observa un patrón emergente, la movilidad intrametropolitana e interregional, que consiste en trabajar en un municipio limítrofe al de residencia, un ejemplo se presenta en Pesquería donde 7 de cada 10 residentes que trabajan se trasladan de manera cotidiana al municipio de Apodaca, un espacio geográfico contiguo.

Analizando la dinámica de la movilidad cotidiana en el principal nodo laboral en la zona metropolitana (Figura 6), destaca:

» Residir en el municipio de Monterrey reduce la movilidad cotidiana ya que la probabilidad de tener un empleo al interior del mismo es alta considerando la concentración en relación con los municipios de la ZMM.

》 Algunos residentes en Monterrey también se desplazan a trabajar a otros municipios, siendo San Pedro Garza García y San Nicolás de los Garza los nodos laborales más importantes: en segundo lugar, se encuentran los nodos de Apodaca y Guadalupe; y en tercer lugar los nodos de General Escobedo, Santa Catarina y García.

» Monterrey es para la población trabajadora de 14 de los 17 municipios que integran la ZMM uno de los destinos laborales principales y para ocho es el principal fuera del municipio, siendo estos: Apodaca, Cadereyta de Jiménez, García, San Pedro Garza García, General Escobedo, Guadalupe, San Nicolás de los Garza y Santiago. 
El tiempo invertido por las personas en desplazarse en la ZMM está determinado tanto por el diseño de la infraestructura de transporte público y privado, como por una dinámica metropolitana de movilidad, que conjugados acrecientan diferentes tipos de desigualdades en la población (Strazdins et al., 2011).

El 44,6\% de la población trabajadora en la ZMM invierte en promedio hasta treinta minutos en trasladarse del lugar donde reside al centro de trabajo, en tanto $30,3 \%$ ocupa entre 31 minutos y una hora, $13,4 \%$ gasta en esta misma acción más de una hora. Estos datos describen el comportamiento de la población en su conjunto.

Sin embargo, el tiempo de viaje individual puede diferir considerablemente al considerar otras variables, por ejemplo, Jurado y Pereira (2010:105) en un estudio realizado en el municipio de García estiman el tiempo promedio de traslado al lugar de trabajo ubicado dentro del perímetro del municipio central Monterrey, identificaron como variables, la distancia y la oferta de transporte, así cuando el viaje inicia en algún punto del municipio de García el trabajador invierte en el desplazamiento 3,30 horas en promedio, en cambio sí el trayecto inicia en Santa Catarina se dedican un poco más de 2 horas de tiempo de viaje.
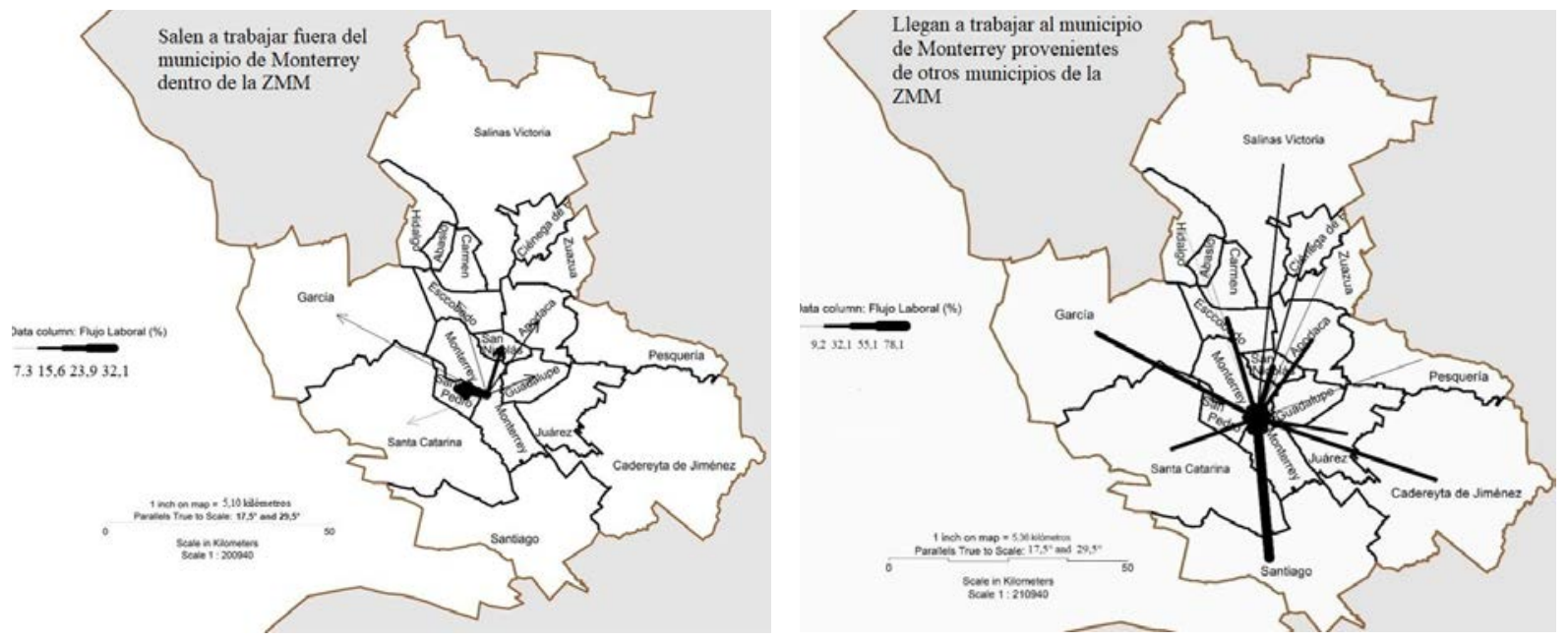

Figura 6. Movilidad de la población trabajadora en el municipio de Monterrey en la ZMM, 2015. Fuente: Elaboración propia con base en los microdatos de la Encuesta Intercensal, 2015, INEGl.

Residir en el mismo municipio donde se trabaja marca una diferencia en el tiempo medio de traslado, siendo este menor en relación con su contraparte, solo 3,9\% de las personas que viven en el mismo municipio donde trabajan ocupan más de una hora y hasta dos para llegar al trabajo, la proporción se multiplica 5,8 veces entre las personas que residen y laboran en un municipio distinto alcanzando 22,7\% (Figura 7). Una pequeña cohorte de personas no se traslada a su centro de trabajo porque viven en el mismo espacio donde laboran, es probable que se trate de trabajadores por cuenta propia con un negocio familiar en casa. 


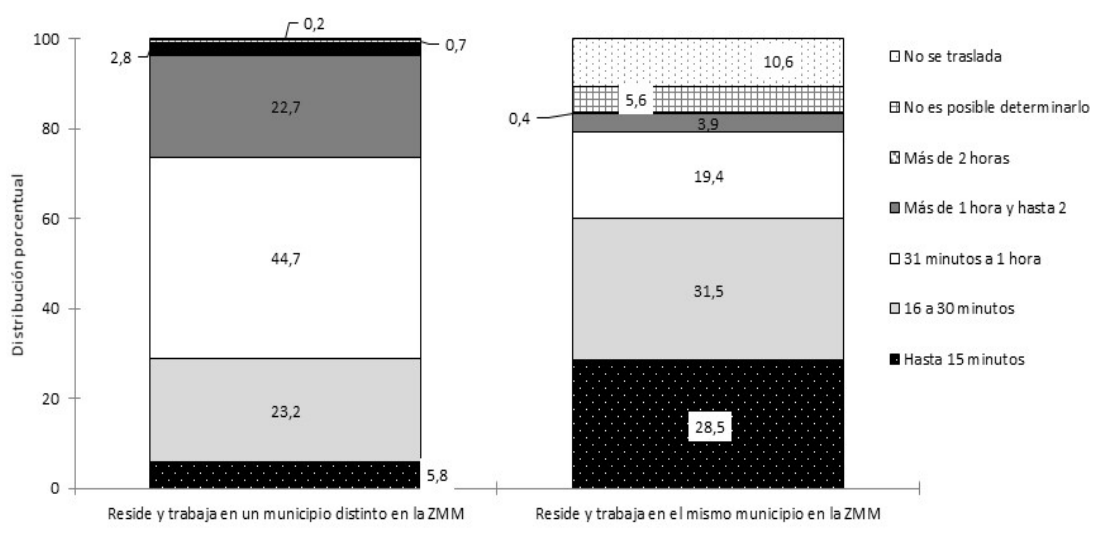

Lugar de residencia

Figura 7. Población residente en la ZMM según ubicación del centro de trabajo y tiempo promedio de traslado, 2015. Fuente: Elaboración propia con base en los microdatos de la Encuesta Intercensal, 2015, INEGI.

La ubicación del empleo es un factor diferenciador en el tiempo promedio de traslado independiente al municipio donde se resida, si este se encuentra ubicado en algún municipio limítrofe en la ZMM como en el caso de Pesquería y Santiago. En caso de Pesquería cuatro de cada diez personas invierten más de una hora en el viaje en el traslado al centro de trabajo, proporción que se eleva hasta 6 de cada 10 entre los que se dirigen al municipio de Santiago.

El municipio de residencia habitual juega un papel destacado en el tiempo consumido en el traslado al centro de trabajo, siendo mayor cuando se vive en Cadereyta, Ciénega de Flores, Juárez, El Carmen y García, debido entre otros factores a la falta de vías de comunicación intermunicipales, mala planeación y gestión de las rutas del transporte público (Jurado y Pereira, 2010).

El principal medio de transporte utilizado en la ZMM para trasladarse al trabajo es el transporte público con un 41,2\% llámese autobús taxi o metro, le sigue casi con la misma proporción 39,4\% vehículo particular, van al centro de trabajo caminando o en bicicleta $8,5 \%$ y utilizan el transporte laboral ${ }^{4} 8,5 \%$. Al comparar estos datos con los de Quintanilla (1995) y Larralde (1997) para el año 1990, se aprecia que en 15 años disminuyó el uso del transporte público en diez puntos porcentuales, mientras que el automóvil y otros medios activos como a pie o en bicicleta subieron, resultado de las pésimas condiciones del servicio de transporte público.

Dependiendo de la distancia entre el lugar de residencia y del centro de trabajo hay variaciones en el medio de transporte, cuando se vive en el mismo municipio que se trabaja disminuye el uso del transporte público y el vehículo particular, mientras aumenta el uso de medios activos como caminar en comparación con los trabajadores que residen y trabajan en un municipio distinto en la ZMM (Figura 8). Estos datos corroboran lo encontrado por Marquet y Miralles-Guasch (2015) quienes demostraron que cuando las actividades humanas están cercas se incrementan el uso de medios de transporte activos. 


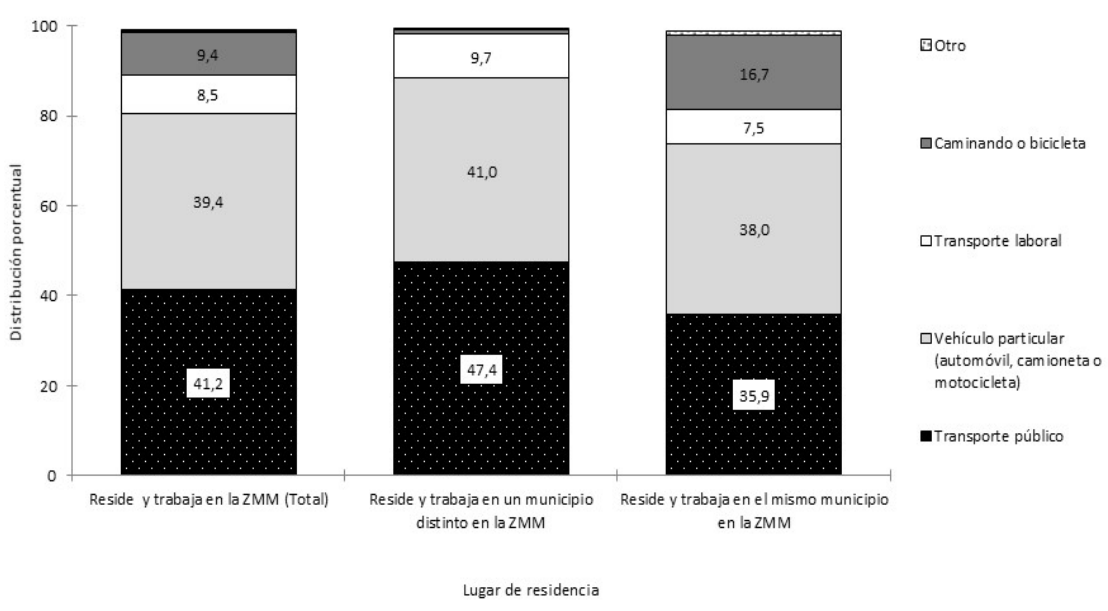

Figura 8. Medio de transporte utilizado para trasladarse al centro de trabajo de la población residente en la ZMM, 2015. Fuente: Elaboración propia con base en los microdatos de la Encuesta Intercensal, 2015, INEGI.

Los datos muestran una correlación positiva entre la ubicación de los espacios de residencia y trabajo con la decisión sobre el medio de transporte utilizado para el traslado diario, lo cual podría estar también relacionado con algunas conductas subyacentes, incluidos cambios demográficos y actitudinales a favor de los medios activos de movilidad (Keyes y Crawford-Brawn, 2008).

El uso del transporte público se incrementa entre la población trabajadora en casi todos los municipios de la ZMM cuando el lugar de trabajo se encuentra en un municipio distinto al de residencia, en comparación con la población que reside y trabaja en el mismo municipio (Figura 9). Exceptuando a los trabajadores residentes en el municipio de Monterrey donde las personas privilegian como principal medio de transporte hacia otros municipios el automóvil.

Para más del 50\% de la población trabajadora residente en San Pedro Garza García, Monterrey, San Nicolás de los Garza y Santiago el principal medio de transporte para ir al centro de trabajo fue el automóvil. En contraparte, con un porcentaje similar el transporte público fue el medio de traslado utilizado entre los residentes de Cadereyta, El Carmen, Ciénega de Flores, García, Juárez, Pesquería, Salinas Victoria y Santa Catarina (Figura 9).

El ingreso promedio por trabajo esta correlacionado de manera directa con el medio de transporte usado para trasladarse al centro de trabajo en la ZMM, tanto entre las personas que residen y trabajan en el mismo municipio como su contraparte personas que residen y trabajan en un municipio distinto. 

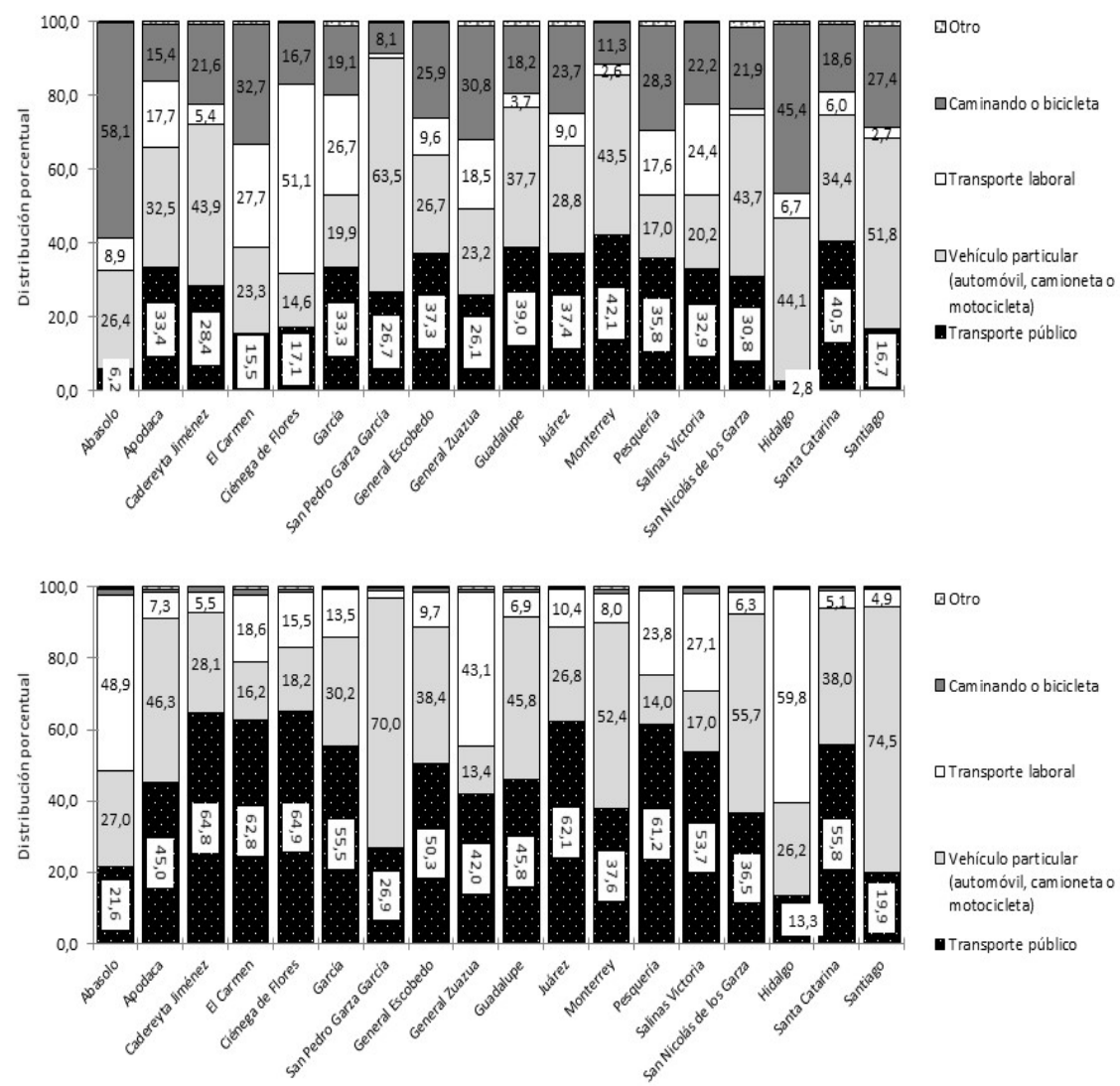

Diferente municipio de residencia yempleo en la ZMM

Figura 9. Medio de transporte utilizado para trasladarse al centro de trabajo según municipio de residencia en la ZMM, 2015. Fuente: Elaboración propia con base en los microdatos de la Encuesta Intercensal, 2015, INEGI.

Así, las personas que usan el vehículo particular como principal medio de traslado al centro de trabajo duplican en ingreso medio mensual en comparación con las personas que realizan el traslado en transporte público, cuando se va caminando o en bicicleta al trabajo se tiene un menor ingreso promedio mensual (Cuadro 1). Este resultado coincide con lo encontrado por Fuentes (2009) en Ciudad Juárez, pero contrasta con estudios elaborados en países desarrollados donde se sugieren cambios en la relación entre ingresos y el uso del vehículo particular (Keyes y Crawnfod-Brown (2018).

Cuadro 1. Medio de transporte utilizado para trasladarse al centro de trabajo en la ZMM según ingreso promedio 2015. Fuente: Elaboración propia con base en los microdatos de la Encuesta Intercensal, 2015, INEGI.

\begin{tabular}{|l|c|c|c|}
\hline \multirow{2}{*}{$\begin{array}{l}\text { Medio de transporte utilizado para ir al centro de } \\
\text { trabajo }\end{array}$} & \multicolumn{3}{|c|}{ Reside y trabaja en la ZMM } \\
\cline { 2 - 4 } & Total & $\begin{array}{c}\text { Mismo } \\
\text { Municipio }\end{array}$ & $\begin{array}{c}\text { Diferente } \\
\text { municipio }\end{array}$ \\
\hline Transporte público & $\$ 6,231$ & $\$ 6,437$ & $\$ 6,231$ \\
\hline $\begin{array}{l}\text { Vehículo particular (automóvil, camioneta o } \\
\text { motocicleta) }\end{array}$ & $\$ 13,066$ & $\$ 13,588$ & $\$ 13,066$ \\
\hline Transporte laboral & $\$ 6,594$ & $\$ 6,766$ & $\$ 6,594$ \\
\hline Caminando o Bicicleta & $\$ 5,304$ & $\$ 5,405$ & $\$ 5,304$ \\
\hline Otro & $\$ 7,669$ & $\$ 9,188$ & $\$ 7,669$ \\
\hline
\end{tabular}


La posesión de algún vehículo particular dentro de los hogares en las entidades fronterizas del norte del México como Nuevo León estado en donde se ubica la ZMM suele asociarse con el sueño americano "cada familia un auto", el automóvil es considerado un artículo de fácil acceso debido a la posibilidad de adquirir automóviles del mercado estadounidense, aunque sea en condiciones deterioradas. En la ZMM el automóvil particular es visto como un medio fundamental de transporte para acceder a recursos territoriales, de acuerdo con Guillen (2007) la disponibilidad de por lo menos un automóvil por vivienda en las zonas metropolitanas fronterizas es del $70 \%$ mientras en las zonas metropolitanas no fronterizas la cifra cae a $55 \%$.

Trasladarse desde el lugar donde se vive al centro de trabajo en automóvil particular, representa un elemento de desigualdad socioeconómica (Soto, 2017), debido a las malas condiciones del transporte público los hogares que no disponen de automóvil están en desventaja. El caso extremo de desigualdad se observa entre los residentes del municipio de San Pedro Garza García, cuando se utiliza como medio traslado al centro de trabajo el automóvil se tienen ingresos promedio 443,1\% mayor en comparación a cuando se utiliza el transporte público (Figura 10). La tendencia descrita es observable en los 17 municipios restantes de la ZMM.

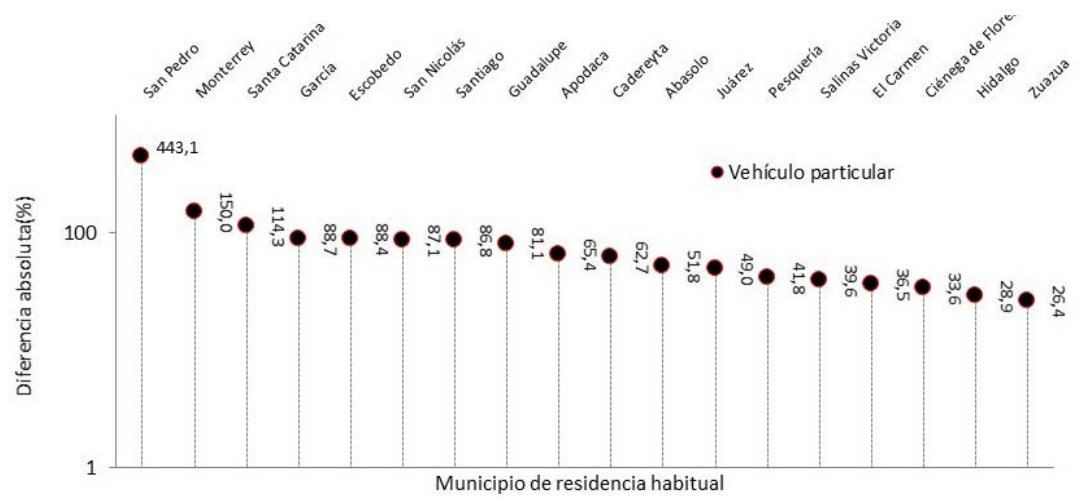

Figura 10. Brecha porcentual absoluta en el ingreso promedio de los trabajadores en la ZMM que se trasladan al centro de trabajo en vehículo particular respecto a los que utilizan transporte público, 2015. Fuente: Elaboración propia con base en los microdatos de la Encuesta Intercensal, 2015, INEGI.

Utilizar el transporte laboral no es un indicador de percibir menos ingresos por trabajo en comparación con trasladarse en transporte público, como se registra entre los trabajadores residentes en siete municipios de la ZMM: San Pedro Garza García, Monterrey, Santa Catarina, General Escobedo, San Nicolás de los Garza, Guadalupe y Cadereyta de Jiménez.

Al utilizar las variables tiempo de viaje y medio de transporte (Figura 11), para analizar la movilidad cotidiana de la población residente en la ZMM si el centro de trabajo se ubica cerca del lugar de residencia sobresale que:

》Una opción para trasladarse es usar medios activos como caminar o la bicicleta, así lo manifiesta $30,1 \%$ del total y $34,4 \%$ de los neoleoneses residentes en el mismo municipio donde labora.

»El vehículo particular es uno de los medios de transporte más utilizado sobre todo cuando los tiempos de traslado al centro de trabajo son de hasta 15 minutos, a partir de este punto comienza a disminuir. Lo que muestra que las estrategias de movilidad y la elección sobre el medio de transporte están relacionadas con el tiempo dedicado al desplazamiento. 

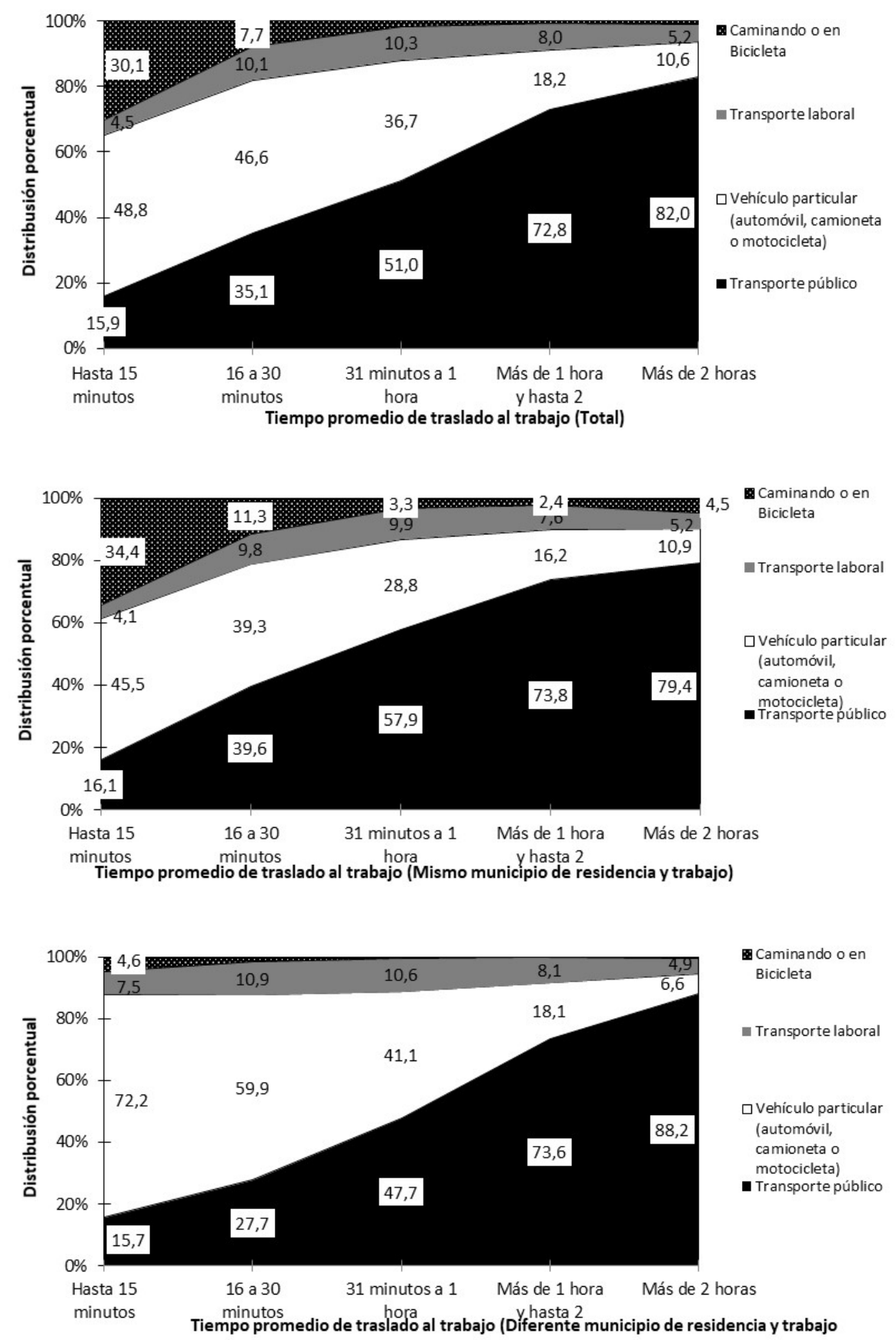

Figura 11. Población residente en la ZMM según tiempo promedio de viaje y medio de transporte utilizado para llegar al centro de trabajo, 2015. Fuente: Elaboración propia con base en los microdatos de la Encuesta Intercensal, 2015, INEGI.

El transporte laboral es utilizado por la población de la ZMM cuando es una prestación ofertada por el empleador, tiene un impacto directo en la movilidad cotidiana ya que significa un ahorro en el tiempo de traslado y en el gasto individual diario del trabajador. El transporte público en la ZMM es costoso en comparación con otras ZM de México (COLEF, s/f), por ejemplo, un trabajador que se traslada desde el municipio de García hasta el sur en el municipio de Monterrey gasta en promedio $\$ 60,00$ diarios, si trabajará seis días a la semana cuando finalizaría el mes habría gastado más de $\$ 1.500,00$, cantidad equivalente al 70\% del salario mínimo mensual vigente. 
Los medios activos de traslado caminar o utilizar la bicicleta no son una opción de traslado al centro de trabajo cuando no se reside en el mismo municipio donde se trabaja, en este caso el trasporte público es la mejor elección para realizar el viaje, este medio se incrementa en la medida que aumenta el tiempo de traslado a la par la utilización del vehículo particular comienza a ser una opción menos utilizada, por ejemplo en un trayecto de dos horas $88,6 \%$ viaja en trasporte público y solo $6,6 \%$ usa el vehículo particular.

\section{Conclusiones}

En el año 2015 la población trabajadora de la ZMM mostró una intensa movilidad entre el lugar de residencia habitual y el centro de trabajo, así como diferencias en el nivel de accesibilidad según tipo de transporte derivado de la distancia entre la vivienda de residencia y el lugar de trabajo, nivel de ingresos, entre otros. En un espacio geográfico de $7.627,5 \mathrm{Km} 2$ cuatro de cada diez personas en promedio trabajan en un municipio diferente al de residencia habitual, proporción que se eleva a siete de cada diez personas entre los residentes del municipio de Pesquería un espacio geográfico de reciente incorporación a la ZMM que hasta el lustro anterior era periférico y en donde se ha trasladado en años recientes el crecimiento poblacional de la metrópoli, producto de la masificación en la construcción de vivienda nueva y la expansión industrial tras el asentamiento de la industria coreana KIA MOTORS. Coadyuvado a la consolidación de una configuración territorial extendida y fragmentada de la ZMM, donde las distancias entre el lugar de residencia y el centro de trabajo son cada vez más largas en consecuencia se incrementa la movilidad cotidiana de la población relacionada con el trabajo.

Residir y trabajar en el mismo municipio facilita la vida de las personas en la ZMM, los tiempos de traslado se reducen de forma considerable en comparación con su contraparte personas que viven en un municipio y se trasladan todos los días aún centro de trabajo ubicado en otro municipio, principalmente a los municipios de Monterrey, San Pedro Garza García, San Nicolás de los Garza, Apodaca y Guadalupe, en dónde se ubican los nodos laborales más importantes del estado.

Los principales medios para trasladarse al centro de trabajo en la ZMM son el trasporte público y el vehículo particular, pero conforme los tiempos de traslado se alargan es usado más el transporte público, probablemente se trate de una estrategia de ahorro de las personas que tratan de gastar lo menos posible del sueldo en el traslado hacia el trabajo.

Opciones alternativas de medio activo de traslado entre el lugar de residencia y el centro de trabajo como caminar o utilizar la bicicleta se eligen cuando la distancia entre ambos es corta. Las distancias y el entorno construido son importantes para la formación de actitudes favorables hacia los medios activos de transporte. El transporte laboral proporcionado por algunas empresas a sus trabajadores es ampliamente utilizado en la ZMM, ya que representa un ahorro para los trabajadores, en uno de los lugares de México donde el costo del transporte público es de los más costosos.

En la ZMM el vehículo particular es un medio de transporte imprescindible para la movilidad debido a la estructura espacial dada, además como en toda entidad fronteriza con Estados Unidos se asocia con el sueño americano y la calidad de vida. No obstante, también está relacionado con las características socioeconómicas de las personas, el vehículo particular continúa siendo un bien que denota la desigualdad en los ingresos por trabajo, las personas que no poseen un automóvil particular se encuentren en desventaja debido a la mala calidad del transporte público. 
Cada año se suman al parque vehicular motorizado de la ZMM cientos de unidades lo que hará cada vez más caótica la movilidad, porque las vialidades continúan siendo las mismas no crecen, algunos problemas comienzan a ser evidentes en la movilidad en las horas pico, un trayecto de 15 minutos llega alargarse hasta 2 horas. Deben realizarse esfuerzos para diseñar un sistema de transporte colectivo y medios activos de transporte eficientes en la ZMM.

Las estrategias de movilidad relacionadas con el trabajo en la ZMM responden a la configuración territorial y a las características de las personas determinando su nivel de accesibilidad y capacidad de movilidad, como se demostró en esta investigación. Sin embargo, se necesita indagar en la experiencia subjetiva de la movilidad relacionada con el trabajo. 


\section{Q Bibliografía}

" Acuña, B. y Graizbord, B. (1999). Movilidad cotidiana de trabajadores en el ámbito megalopolitano de la Ciudad de México. En Ramírez, B., y Delgado, J. (coords.). Transiciones, territorio y cultura en la Ciudad de México, tomo I. Ciudad de México: Universidad Autónoma Metropolitana/Plaza y Valdés.

»Anguiano, M. E. (2005). Cross-Border Interactions: Population and Labor Market in Tijuana. The Ties that Bind Us. Mexican Migrants in San Diego County. La Jolla, San Diego: University of California.

»Bautista, A. (29 abril 2019). En pleno regreso a clases transportistas dejan varados a regios en NL. La Razón. Consultado el 30 de abril del 2019 en: https:// www.razon.com.mx/mexico/transporte-publico-transportistas-nuevo-leonmonterrey-paro-de-labores-crisis-caos-vial-varados-regios-regreso-a-clasessin-servicio-area-metropolitana-regios/

»Badoe, D., y Miller, E. J. (2000). Transportation-land-use interaction: empirical findings in North America, and their implications for modeling. Transportation Research Part D: Transport and Environment, 5 (4), 235-263.

»Bedoya, Y., Jáuregui Díaz, J. A., Ávila Sánchez, M. J., y Picazzo Palencia, E. (2018). Recent trend in internal migration in Nuevo Leon, Mexico. ESPACIO I+D, Innovación más Desarrollo, VII (18), 122-135.

»Canales, A., Canales, M. y Hernández, M. (2017). Trabajo, territorio y movilidad cotidiana en Chile. Un estudio comparativo según tipos de conmutación laboral. Revista Contraste Regional, 5 (10), 27-50.

»Casado, J. (2008). Estudios sobre movilidad cotidiana en México. Scripta Nova, 12(273).

»Cattan, N. (18 de septiembre de 2018). HIPERGEO. Recuperado el 22 de marzo de 2019, de Movilidad espacial: http://www.hypergeo.eu/spip.php?article543\#

» $\operatorname{COLEF}(\mathrm{s} / \mathrm{f})$. El transporte público en Monterre la mala calidad se paga caro. Recuperado 10 de febrero del 2020 de https://www.colef.mx/opinion/eltransporte-publico-en-monterrey-la-mala-calidad-se-paga-caro

»Camagni, R., Gibelli, M. C., Rigamonti, P., y Cristina, M. (2002). Urban mobility and urban form: the social and environmental costs of different patterns of urban expansion. Ecological Economics, 40(2), 199-216.

»CONAPO, SEDESOL e INEGI. (2018). Delimitación de las zonas metropolitanas de México 2015 (Primera ed., Vol. I.). Ciudad de México: CONAPO. Recuperado el 16 de noviembre de 2018, de https://www.gob.mx/conapo/documentos/ delimitacion-de-las-zonas-metropolitanas-de-mexico-2015

"Delclòs, X. (2019). The multiple dimensions of daily travel time: empirical findings in the Barcelona Metropolitan Region. Ph. D. Dissertation. Universitat Autònoma de Barcelona.

» Fuentes, C. (2009). La estructura espacial urbana y accesibilidad diferenciada a centros de empleo en Ciudad Juárez, Chihuahua. Región y Sociedad, XXI (44), 117-144.

» Garza, G. (1994). El proceso de metropolización en Monterrey. Hay que planear a largo plazo. DEMOS (7), 17-18. 
» Graizbord, B. (2004). Metropolitan mobility: migration and commuting. En Pacione, M. Changing cities. International perspectives (p. 79-88). Glasglow: IGU Urban Commission y Stratchclyde University Publishingp.

" Guillen, T. (2007). Frontera Norte: los contrastes de la calidad de vida. Revista Mexicana de Política Exterior (81), 9-32.

» Gould, P. (1985). The Geographer at Work. London: Routledge.

" Hägerstrand, T. (1953). Innovation diffusion as a spatial process. Chicago: Univ. of Chicago Press.

» Hägerstraand, T. (1970). What about people in regional science? Papers in regional science, 24(1), 7-24.

» INEGI. (2018). Encuesta Intercensal 2015, Marco Conceptual (Primera ed., Vol. I). Aguascalientes, Aguascalientes, México: INEGI.

»Islas, V. (2000). Llegando tarde al compromiso: la crisis del transporte en la Ciudad de México. México D.F.: El Colegio de México.

"Isunza, G. (2010). Política de vivienda y movilidad residencial en la Ciudad de México. Estudios Demográficos y Urbanos, 25 (74), 277-316.

» Jurado, M., y Pereira, K. (2010). La gestión del servicio de transporte público. El caso del municipio de García y su relación con la movilidad geográfica laboral metropolitana. En Palacios, L. (Ed.) Cuando México enfrenta la globalización. Permanencia y cambio en el Área Metropolitana de Monterrey. Ciudad de Monterrey: UANL y COLEF.

» Keyes, A., y Crawford-Brawn, D. (2008). The changing influences on commuting mode choice in urban England under Peak Car: A discrete choice modelling approach. Transportation Research Part F: Traffic Psychology and Behaviour, 58, 167-176.

» Kaufmann, V., y Jemelin, C. (2004, October). La motilité, une forme de capital permettant d'éviter les irréversibilités socio-spatiales. En Colloque de géographie sociale Espaces et Sociétés aujourd'hui, Rennes.

"Law, R. (1999). Beyond women and transport : towards new geographies of gender and daily mobility. Progress in Human Geography, 23 (4), 567-588.

"Larralde, A. (1997). Los desplazamientos cotidianos de los habitantes en el Área Metropolitana de Monterrey. Estudios Demográficos y Urbanos, 12 (3), 473-520.

"Lindón, A. (2020). Experiencias espaciales femeninas en los desplazamientos cotidianos. Revista Mexicana de Sociología, 82 (1), 37-63.

»Noort, H. (2010). From rural village to commuter town: Voorschoten 1945-1970. Voorschoten: Van Noort.

» Marquet, O., y Miralles-Guasch, C. (2015). The Walkable city and the importances of the proximity environments for Barcelona's everyday mobility. Cities, (42), 258-266.

»Metz, D. (2008). The Myth of Travel Time Saving. Transport Reviews, 28(3), 321336.

»Mohan, R. (1979). Urban Economics and Planning Models. Nueva York: World Bank.

» Rose, G. (1993). Feminism and geography: The limits of geographical knowledge. Cambridge: Polity Press. 
》Quintanilla, E. (1995). El servicio de transporte. En Garza, G. Atlas de Monterrey (p. 235-245). México: Gobierno del estado de Nuevo León-Universidad Autónoma de Nuevo León-Instituto de Estudios Urbanos de Nuevo León-El Colegio de México.

»Sobrino, J. (2007). Patrones de dispersión intrametropolitana en México. Estudios Demográficos y Urbanos, 22 (66), 584-617.

»Soto, K. (2015). Hacia una aproximación de la teoría de la localización residencia. La vivienda unifamiliar de segmento medio del Área Metropolitana de Monterrey, 2005-2010. Tesis de Doctorado. Universidad de Nuevo León. Facultad de Arquitectura.

»Soto, K. (2017). Movilidad urbana y diferenciación socioespacial en el Área Metropolitana de Monterrey. Red Urban, III (3), 21-29.

»Strazdins, L., Griffin, A. L., Broom, D. H., Banwell, C., Korda, R., Dixon, J., ... Glover, J. (2011). Time scarcity: Another health inequality? Environment and Planning, 43(3), 545-559.

"Vega, G. (2016). Población commuter de la frontera norte: el caso de MexicaliCalexico y Tijuana-San Diego. Estudios Demográficos y Urbanos, 31(91), 207-238.

»Walker, J. G. N. (1976). Bikeways for Flower Mound: A Proposed System of Recreational and Commuter Bikeways for the Town of Flower Mound. Texas: Institute of Urban Studies, University of Texas at Arlington.

\section{José Alfredo Jáuregui Díaz / jose.jaureguid@uanl.edu.mx}

Licenciado en Sociología (Universidad Autónoma de Aguascalientes), Maestro en Demografía (El Colegio de la Frontera Norte) y Doctor en Demografía (Universidad Autónoma de Barcelona, España). Publicó artículos en revistas de especialidad sobre migración y población. Profesor Investigador, Universidad Autónoma de Nuevo León - Instituto de Investigaciones Sociales. México.

\section{María de Jesús Ávila Sánchez / maria.avilasnz@uanl.edu.mx}

Licenciada en Sociología (Universidad Autónoma de Aguascalientes), Maestra en Demografía (El Colegio de la Frontera Norte) y Doctora en Ciencias Sociales (Universidad de Leiden, Países Bajos). Publicó artículos en revistas de especialidad sobre población y migración. Profesora Investigadora, Universidad Autónoma de Nuevo León - Instituto de Investigaciones Sociales. México.

\section{Rodrigo Tovar Cabañas / rod_geo77@hotmail.com}

Licenciado en Geografía (Universidad Nacional Autónoma de México), Maestro en Geografía (Universidad Nacional Autónoma de México), Doctor en Geografía (Universidad Nacional Autónoma de México). Publicó artículos en revistas de especialidad sobre Vulnerabilidad y territorio. Profesor Investigador, Universidad Autónoma de Nuevo León - Instituto de Investigaciones Sociales. 